\title{
Л.И. Шерстова
}

\section{ЗНАЧЕНИЕ ЭТНОНИМОВ В СТРУКТУРИРОВАНИИ «КОЧЕВЫХ ИМПЕРИЙ» ЕВРАЗИИ}

\begin{abstract}
Рассматривается социальная структура «кочевых» народов Центральной Азии и Южной Сибири. Ставится проблема о значимости этнонима в сохранении этнического единства тюрко-монгольскими народами и его роли в дальнейшем структурировании их социумов как в рамках собственной государственности, так и в условиях вхождения в состав иноэтничных полиэтничных государств. Делается вывод о необходимости дальнейшего осмысления роли этнонимов и сущности социальнополитических институтов, ими обозначенных, в традиционных обществах народов Евразии.

Ключевые слова: Центральная Азия; Евразия; «кочевые» народы; этноним; государственность; род; политика «невмешательства»; традиционное общество.
\end{abstract}

В отличие от оседлых обществ, для кочевых народов территория сама по себе не была базой для воспроизводства и дальнейшего функционирования социально-политических институтов. В условиях подвижного скотоводческого образа жизни, сменявших друг друга «кочевых империй», сопровождавшихся перетасовками человеческих коллективов, сохранение этносоциального единства не могло базироваться на привязанности к конкретной территории или единой экономике. Связи с этнической или производственной территорией были менее зримы внешне - они не определялись пространством «возделанной земли» и не носили характера постоянного присутствия.

Этническая территория была совокупностью различных маркеров, чаще природного происхождения, которые были «втянуты» в реальную или мифическую историю народа. Названия гор, рек, перевалов связывались с именами героев или божеств, с событиями прошлого, с историей отдельных семей и их потомков. В условиях ограниченного использования письменности «своя» территория сама по себе была источником знания о прошлом, и сезонные ее посещения оживляли связи между поколениями, а ритуалы закрепляли внутриэтнические связи.

Ядром же государственного строительства были сами человеческие коллективы, а объединяющим началом для них служили названия различных этнических образований, которые осмысливались как показатели общности происхождения, основанного на реальных или вымышленных кровнородственных связях, что находило отражение в наличии «родовой» организации и развитых генеалогиях всех «степных», вернее, кочевых народов - от древних евреев до более поздних казахов, туркмен, алтайцев и т.д.

В советской историографии проблема генезиса государственности у кочевых народов решалась либо в рамках универсальной концепции феодализма и, следовательно, собственность на землю была главным условием этого процесса, либо выдвигалось мнение относительно собственности на скот. Одним из первых ученых, кто обратил внимание на значимость человеческих коллективов как фактора государствообразова- ния, был Е.М. Залкинд. В 1970-х гг. он писал: «Поскольку границы кочевий не были четко определены, то пожалование уделов (при Чингисхане. - Л.Ш.) не могло копировать аналогичный акт в оседлых странах. Там короли жаловали земли вместе с обитающими на них людьми, у номадов же происходило наоборот: люди жаловались вместе с осваиваемыми ими пастбищными территориями» [1. С. 174].

Гибель очередной «кочевой державы», уничтожение правящей элиты могли приводить к временному «всплыванию» архаических социальных институтов. Происходило оживление значимости, казалось бы, уже ставших неактуальными кровнородственных отношений - этой универсальной форме организации социума в условиях слома более развитых социальнополитических структур. Показательно, что и у современных народов общее происхождение, вернее представление об общем происхождении, может выступать этнообъединительным фактором в условиях распада полиэтничных государств. Распад Югославии и СССР убедительно это продемонстрировал. Гражданская идентичность, как идентичность более высокого уровня, уступила место этнической. И народы достаточно развитых полиэтничных государств разошлись по «своим, национальным квартирам».

В более ранние периоды, тем более в результате слома государственности, наступала внешняя архаизация общества, что создавало ложное представление об уровне развития народов степной Евразии. Но накопленные традиции государственности быстро возрождались, когда, вследствие разных причин, та или иная общность, оказавшись в результате «стягивания» своих одноплеменников достаточно многочисленной, «возвышалась» [2. С. 118]. Она брала инициативу создания «нового» государства, в состав которого входили бывшие подданные прежнего, и давала ему свое этническое название. В любом случае народы, находившиеся в сфере влияния уже существовавших политических образований, непроизвольно накапливали и сохраняли элементы государственности. И этот политический опыт, закрепленный в их социально-фискальных институтах, позволял в благоприятных условиях его ре- 
анимировать, продолжая собственное моделирование отдельных элементов государственности даже после вхождения в состав новых, как правило, иноэтничных государств.

Находясь уже в составе Российской империи, тюркоязычное население Горного Алтая продолжало воспроизводить такую политическую модель, которая прочно опиралась на центральноазиатскую (джунгарскую) политическую традицию. Это проявилось не только в бытовании названий административнофискальных единиц - дючин и сохранявшейся джунгарской титулатуры правящей верхушки - зайсанов, демичи, шуленг, но и в дальнейшем структурировании собственного социума, моделью которого была «степная» традиция. Этот механизм проявился в процессе выделения шестой и седьмой дючин в начале XIX в. «Стягивание» телесов, входивших во вторую, преимущественно, кыпчакскую дючину, и майманов, сосредоточенных в пятой - иркитской дючине, неизбежно привело к увеличению их численности и стремлению обособиться в рамках собственных административнофискальных образований. Так, в 1801 г. появилась шестая - телесская, а в 1819 г. - седьмая - майманская дючины.

Важным условием устойчивости аборигенного общества было не только сохранение этнонимов, что наглядно показывают этнографические материалы, так как и алтайские телесы и майманы (найманы) - это осколки средневековых этносов, но бытование родовых и семейных родословных и, соответственно, соблюдение преемственности в наследовании зайсанских должностей. В новой седьмой дючине власть демичи пятой дючины Юдеки Таингашева - бывшего инициатором этого процесса - наследовал его сын - Кускулек Юдекин. Генеалогии зайсанов пяти старых дючин уходили в джунгарское время, когда возглавившие их люди - Кутук, Пуктуш, Куккуш, Пюдюке - выступили сторонниками перехода тюркоязычного населения Горного Алтая в российское подданство. Древность генеалогий, предания о героических делах зайсанов, демичи, богатырей джунгарского времени являлись важнейшим фактором легитимности власти и народного уважения их потомков.

Вплоть до 1880 г. алтайские дючины управлялись наследственными зайсанами. Попытки сократить срок их пребывания в этих должностях российскими властями до трех лет, а также именование их должностей в официальных документах «родовыми старостами» вызвали возмущения в алтайском обществе. Несмотря на то что с этого времени управлявших дючинами выбирали, обычно это превращалось в перевыборы одних и тех же лиц, а сами они по-прежнему именовались в соответствии с джунгарской титулатурой [3. С. 201-204].

Особенностью положения зависимых этнических групп, согласно центральноазиатской политической традиции, сохранявшейся и в евразийском наследии Российского государства, было минимальное вмеша- тельство власти в их внутреннюю структуру при полном и безоговорочном политическом и экономическом подчинении господствующему этносу на протяжении как московского, так и имперского периодов. Этот принцип нашел свое отражение в «Уставе об управлении инородцев» (1822). Несмотря на то что начиная с XVIII в. господствующей концепцией в образованных слоях как европейского, так и российского общества был эволюционизм, теоретически оправдывавший обязательное вмешательство европейцев в жизнь «примитивных» народов, т.е. политику колониализма, в «Уставе...» закреплялись права аборигенов на земли, «ими обитаемые», на создание собственных органов самоуправления (Инородные управы, Степные Думы), у них продолжали функционировать обычное право и свобода вероисповедания [3. С. 128-129]. Истоки принципа «невмешательства» Российского государства во внутреннюю структуру и образ жизни покоренных народов базировались на «ордынской» модели взаимоотношений разноэтничного населения в рамках одного государства [4. С. 10-11].

В Монгольской империи отражением принципа «невмешательства» было существование такого специфического института, как «унаган богол», которым обозначалась завоеванная (присоединенная) иноэтничная общность [5. С. 81]. Это приводило к накоплению зависимым населением опыта государственности при сохранении достаточно архаичных внутренних связей. Такая традиция взаимоотношений подчиненных и господствующих этносов (родов, кланов, племен, патриархальных семей и т.д.) в ситуации гибели последних легко позволяла первым интегрироваться в новые политические образования либо возглавлять их.

При этом правители Степи прекрасно понимали значение этнонима как фактора, символа единства этнической общности, как условие возможного объединения в благоприятных условиях всех ее членов и политического усиления данной общности. Как рассказывается в «Сокровенном сказании», после очередного восстания мэргэдов (меркитов) Чингис-хан «повелел тогда своим <..> мужам иных из мэргэдов погубить, остальных поделить между собой <..> И молвил тогда Чингисхан: “Позволили мэргэдам мы жить вместе, на роды их, на семьи их не делили, они же предательски восстали". И сказав так, Чингисхан поделил средь мужей своих всех недругов-мэргэдов до единого и разослал их в разные концы улуса своего» [6. С. 159]. В другом случае, желая наградить своего подданного, Чингисхан спросил о его желании. И Унгур сказал: «Коли позволено мне выбрать пожалованье хана, хотел бы я всех баягудов, сродников своих, которые теперь разбросаны повсюду собрать и ими править». И повелел Чингисхан: «Что ж, будь потвоему, Унгур. Ты баягудов собери и тысяцким над ними будь» [Там же. С. 177].

В подвижных обществах размеры территории еще не определяли значимость и богатство их правителей. 
Военная сила «кочевых империй» народов Центральной Азии определялась как можно большей численностью зависимого населения и базировалась на величине улуса, под которым понимались не столько размеры территории, сколько «владение», «народ, данный в феодальное держание» [7. С. 118]. В таких аморфных, полиэтничных государствах какие-либо формы насильственной аккультурации со стороны «этноса-элиты» могли оказаться губительными для ее власти, и поэтому от покоренных народов требовались политическая преданность и безусловное выполнение всех указаний при сохранении их внутренней социальной структуры и привычного образа жизни.

Традиция «невмешательства» начала складываться еще в древнем Китае в период Чжоу и, особенно, Хань, когда хуася, а затем и хань, окруженные варварами, вынуждены были налаживать с ними мирные отношения. Заинтересованность в получении престижных товаров заставляла «кочевую» элиту приносить дань как знак зависимости китайскому императору, но полученные подарки по своей стоимости превосходили привезенную дань. То есть это был архаичный дарообмен, при котором отдарок ценился выше подарка. Совершив соответствующие обряды при ханьском дворе, варвары возвращались к себе, продолжая жить по своим обычаям и традициям.

Однако в результате таких контактов, длившихся столетиями, они оказывались втянутыми в экономические, политические, культурные отношения китайского социума, медленно подвергаясь аккультурации, в результате становясь «цивилизованными». Именно в Китае в Раннем Средневековье появилось представление о том, что показателем цивилизованности является не ханьское происхождение, а следование конфуцианству. Следовательно, варвар-конфуцианец становился ханьцем, а ханец, соблюдавший обычаи варваров, - варваром. Таким образом, даже не этническая принадлежность делала «чужого» своим, а следование «универсальному» конфуцианству [8. С. 186-189].

Аналогичный процесс - включение сначала народа, а потом и его территории - хорошо прослеживается при колонизации Сибири русскими в XVII в. Разновременное вхождение в состав России населения и его территории - явление нередкое в сибирской истории. С этим, например, связана проблема определения даты включения Хакасии. Таковой может считаться начало XVII в., когда часть предков хакасов была объясачена из Кетска и Томска, и в одностороннем порядке, на правах ясачных (оставаясь кыштымами енисейских киргизов) вошла в структуру российского общества и государства. Или же 1680 г., когда киргизы признали права на своих подданных и со стороны Москвы, и те стали двоеданцами. Или 1703 г., когда, наконец, тюркоязычные группы Обь-Енисейского междуречья, фактически уже целое столетие платившие русским ясак, заполнили опустевшие после увода киргизов джунгарами земли: качинцы и аринцы с севера, моторы- койбалы с востока, сагайцы с верховьев Томи, бельтиры с юга. При этом сибирские власти не предприняли никаких мер, ограничивавших эти миграции. Наконец, датой вхождения Хакасии в Российское государство можно считать 1707 или 1709 гг., когда основанные русскими Абаканский и Саянский остроги четко обозначили территориальные границы России в бассейне Верхнего Енисея [3. С. 88]. Следовательно, в некоторых случаях следует различать время вхождения в российское подданство сибирских аборигенов и окончательное присоединение территорий, на которых ныне обитают их потомки, что находит прямые аналогии в китайской истории, во взаимоотношениях варваров и ханьцев и объясняется «несвязанностью» населения и территории их обитания при включении в состав иноэтничных государств.

В то же время именно осознание принадлежности к той или иной этнической группе поддерживало ее внутреннее единство. Отсюда характерное для центральноазиатского этнокультурного ареала сохранение этнонимов с Раннего Средневековья. При прерывистой традиции письменности, тем не менее, такие этнонимы, как аба, аз (ач), дубо, байегу, кыргызы, теле (в форме теленгиты, телеуты, телесы) сохранились в Сибири с древнетюркского времени до прихода русских и позже.

Именно стремление «рассеять», «распылить» непокорные народы, разослать их в разные концы улусов правителей привело к тому, что со временем эти осколки некогда крупных этнических общностей становились «строительным материалом» для новых этнических образований, сохраняя при этом свой общий этноним. Так, средневековые кипчаки вошли в состав современных алтайцев, киргизов и казахов, иркиты встречаются у алтайцев, тувинцев, монголов, маймана (найманы) - у алтайцев и казахов и т.д.

Из этого следует, что этнонимы играли важнейшую роль в структурировании подвижных социумов, подтверждением чему является сохраняемая народами Центральной Азии и Южной Сибири так называемая этнонимическая «родовая» организация, особенностью которой является бытование средневековых этнонимов в качестве уже «родовых» названий. Экзогамность таких «родов» не должна вводить в заблуждение и быть аргументом в пользу их примитивности и архаичности. При определенных условиях экзогамность выступала одним из механизмов расширения социальных связей данного коллектива и механизмом структурирования социума в условиях его подвижности. Она помогала сохранить как его внутреннюю целостность, так и способность коллективного встраивания в разнообразные социально-политические системы - от древнетюркских каганатов до Российской империи.

Включение фрагментов предыдущих этносов в форме «родов» в разноэтничные новообразования позволяло «родовой» организации быть не столько «пережитком» прошлого, сколько отражением динамичного этноисторического развития кочевых народов. 
Отождествление отечественными этнографами «родовой организации» тюркоязычных народов Сибири с родовой структурой догосударственных обществ приводило к ошибочному пониманию уровня их социальнополитического развития. Отрицание возможности деградации культуры не вписывалось в формационную (эволюционную) схему хода истории человечества. Деградация комплексного хозяйства сибирских народов вследствие ее переориентации на пушной промысел (ясак) существенно архаизировала их облик к началу XX в. Наличие якобы «родовой» собственности на охотничьи угодья подводило «экономическую» основу для отождествления рода (сеока) народов Саяно-Алтая с первобытным родом, а его экзогамность укрепляла такое понимание.

Между тем «родовая» собственность, прежде всего на территории промысла пушного зверя, как и появившаяся во второй половине XIX - начале XX в. «родовая» собственность на кедрачи, были следствием, в первом случае, ясачной политики государства, во-втором - втягиванием аборигенного населения в российские торговоэкономические отношения, т.е. формирование «родовой собственности» было вызвано внешними факторами. Экономика же подвижных обществ Центральной Азии базировалась на семье, которая была и основной фискальной единицей. Таким образом, «возврат» к «родовой собственности» был следствием политики России, которая архаизировала социально-экономическую структуру аборигенов [3. С. 95-100].

Безусловным признаком «классического» рода является экзогамия. Однако этнографические материалы показывают ее наличие в различных по численности условиях образования социальных общностях, так как экзогамия является важнейшим регулятором вообще всех социальных отношений в традиционных обществах. Вряд ли стоит каждую экзогамную группу относить к «классическому» роду. Так, при численности современных хакасов - около 76 тыс. человек - насчитывается более 150 родов. У корейцев в начале XX в., численность которых была несколько десятков миллионов человек, также сохранялись «роды». Под словом «род» корейцы подразумевали «одинаковое происхождение и одинаковую фамилию». Тем не менее у них было 104 рода и всего 42 фамилии [9. С. 20-28].

Таким образом, вопрос о сущности такого социального института традиционных обществ, как «род», нуждается в серьезном переосмыслении. Это относится и к этнонимическим «родам». Использование термина «вторичный род» не решает проблему его качественного отличия от «первобытного» рода, причины его сохранения в условиях развитой государственности степных народов Центральной Азии и оседлых народов Восточной Азии, а также его роль в структурировании государственности.

Вопрос о языковой принадлежности таких «родов» не может решаться однозначно: в условиях подвижности общества и особенностей политических процессов смена языка не влекла за собой обязательного изменения этнонима и отказа от прежнего образа жизни. Минимальное вмешательство господствующих этносов полиэтничных государств Центральной Азии во внутренние отношения подвластных им народов приводило к тому, что, подчинившись политически и экономически, они продолжали воспроизводить свою культурную специфику, даже сменив языковую принадлежность. Монголоязычные майманы эпохи Чингисхана, потеряв впоследствии этническое единство, в качестве уже тюркоязычных родов вошли в состав современных казахов и алтайцев, но при этом сохранили свой средневековый этноним.

Более того, имеются примеры, когда этносы (этнические группы), использующие один этноним, могли отличаться языковой принадлежностью и хозяйственными характеристиками. Так, разные группы урянхайцев Восточного Казахстана, Горного Алтая и Западной Монголии середины XVIII в., несмотря на наличие общего этнонима, существенно отличались друг от друга. В хозяйственном плане урянхайцы верхнего Иртыша, как свидетельствует русский документ того времени, делились на две группы. «Уранхайцы бывают пешие и питаются сараною и марьиным корнем; которые же имеют скот, те стоят по местам, где есть корм для скота и звериный промысел» [10. С. 156]. Показательно, что в документе не смешиваются два хозяйственнокультурных типа, и если второй соответствует подвижному скотоводству и соотносится с центральноазиатским «кочевым миром», то первый является достаточно полным описанием образа жизни охотников и собирателей горно-таежной зоны Сибири, в том числе и жителей «страны Баргуджин-Токум», т.е. урянхайцев Прибайкалья [11. С. 121-124]. Возможно, что уже тогда среди них были распространены как тюркские, так и монгольские языки.

Поэтому определять языковую принадлежность тех или иных этнических групп Центральной Азии и Южной Сибири можно только применительно к конкретному хронологическому периоду. При этом сохранение этнонима не может свидетельствовать о сохранении прежней языковой или культурной принадлежности. Ситуация, при которой утрачивается язык, но сохраняется этноним, а значит, удерживается и определенное этническое единство, еще раз подчеркивает его значимость в подвижном обществе, что и определяло устойчивость этнонимики народов Центральной Азии и Южной Сибири.

Итак, значение этнонима и социально-политических институтов, которыми он обозначался, для народов степной Евразии заключалось как в сохранении представления об определенной этнической целостности, несмотря на пространственную «распыленность», так и в понимании его как важнейшего фактора структурирования общества и его дальнейшего этноисторического развития. 


\section{ЛИТЕРАТУРА}

1. Залкинд Е.М. Очерк генезиса феодализма в кочевом обществе. Барнаул : Изд-во Алт. ун-та, 2012. 242 с.

2. Савинов Д.Г. Народы Южной Сибири в древнетюркское время. Л. : Изд-во ЛГУ, 1984. 174 с.

3. Шерстова Л.И. Тюрки и русские в Южной Сибири: этнополитические процессы и этнокультурная динамика XVII - начала XX века. Новосибирск, 2005.

4. Шерстова Л.И. Восприятие русской власти аборигенами Сибири в XVII в.: евразийский аспект // Сибирские исторические исследования. 2013. № 1. С. 8-17.

5. Владимирцов Б.Я. Общественный строй монголов. М. ; Л., 1934. 233 с.

6. Сокровенное сказание монголов // Чингисиана. Свод свидетельств современников. М. : ЭКСМО, 2009. С. $17-256$.

7. Федоров-Давыдов Г.А. Общественный строй Золотой Орды. М., 1973. 178 с.

8. Шерстова Л.И. Россия и Китай: подходы к переосмыслению полиэтничности // Востоковедные исследования на Алтае. Барнаул : Изд-во Алт. ун-та, 2014. Вып. VIII. C. 185-189.

9. Конрад Н.И. Неопубликованные работы, письма. М. : РОССПЭН, 1996. 544 с.

10. Потанин Г.Н. Пространство Северного Казахстана и Сибири по документальным публикациям Г.Н. Потанина. Томск : Том. гос. ун-т, 2013. $314 \mathrm{c}$.

11. Рашид-ад-Дин. Сборник летописей. М. : Ладомир, 2000. Т. 1, кн. 1. 221 с.

Sherstova Lyudmila I. Tomsk State University (Tomsk, Russia).E-mail: sherstova58@mail.ru

THE SIGNIFICANCE OF ETHNONYMS IN THE STRUCTURING OF EURASIAN 'NOMADIC EMPIRES'.

Keywords: Cenral Asia; Eurasia; 'nomads'; etnonym; state system; clan; principle of 'non-intervention'; traditional society.

In the present article the problem of the significance of 'clans' ethnonymic names in 'nomadic' societies in Eurasia is discussed based on the analysis of Russian documents of the XVII-XX centuries, Mongolian written sources of the XIII century, ethnographic materials that were collected in Gorny Altai in the XX century. In contrast to settled societies, for nomads the territory was not the basis for reproduction and the further functioning of socio-political institutions. In conditions of mobile cattle-breeding way of life, 'nomadic empires' that replaced one after another and it was accompanied by the moving of human groups, the preservation of ethno-social unity could not be based on the attachment to a specific territory or a single economy. Human groups were the core of state-building. Names of different ethnic groups were unifying principle for these groups. Names of different ethnic groups were perceived as indicators of common origin that based on real or invented kinship. It was reflected in the presence of 'clan' organization and advanced genealogies of all 'steppe peoples', more precisely, of all nomads (from ancient Hebrews to later Kazakhs, Turkmens, Altai people, etc.). According to the Central Asia political tradition, dominant ethnic groups' principle of non-intervention to internal socio-political structure of joined (conquered) peoples was a peculiarity of subordinate ethnic groups' status. The principle of 'non-intervention' began to take shape in Ancient China during Zhou dynasty and especially during Han dynasty, when Huaxia and then Han people were surrounded by barbarians and were compelled to establish peaceful relations with them. In the Mongol Empire the principle of 'non-intervention' was reflected in the presence of specific institution as 'unagan bogol', which indicated conquered (joined) 'other ethnic' group. It led to the accumulation of statehood experience by subordinate people in situation of preserving quite archaic internal relations. This tradition of relations between subordinate and dominant ethnic groups (kin, clans, tribes, patriarchal families etc.) allowed subordinate ethnic groups quickly create their own state or easily became a part of 'other-ethnic' empires in case of dominant ethnic group's fall. The principle of 'nonintervention' is reflected in Russian policy relating to Aboriginal people in Siberia since the XVII century. Later it was recorded in the 'Charter on the management of foreigners' (1822). As a result of this policy the peoples of Siberia preserved ethnonymic names of fiscal and administration institution, which originated from ancient Turkic time, until the beginning of the XX century and they also continued to structure their societies on the basis of 'Central Asian model' but as a part of Russia. For the steppe people of Eurasia the significance of ethnonym and socio-political institutions which ethnonym indicated was in preserving the idea of particular ethnic unity, in spite of territorial 'dispersion', and also was in perception the ethnonym as an important factor in structuring society and state and its further ethno-historical development.

\section{REFERENCES}

1. Zalkind, E.M. (2012) Ocherk genezisa feodalizma v kochevom obshchestve [An essay of the genesis of feudalism in the nomadic society]. Barnaul: Altai State University.

2. Savinov, D.G. (1984) Narody Yuzhnoy Sibiri v drevnetyurkskoe vremya [The peoples of South Siberia in the ancient times]. Leningrad: Leningrad State University.

3. Sherstova, L.I. (2005) Tyurki i russkie v Yuzhnoy Sibiri: etnopoliticheskie protsessy i etnokul'turnaya dinamika XVII - nachala KhKh veka [The Turks and Russian in Southern Siberia: The ethno-political and ethno-cultural dynamics of the processes of the 17th - early 20th centuries]. Novosibirsk. 2005.

4. Sherstova, L.I. (2013) Vospriyatie russkoy vlasti aborigenami Sibiri v XVII v.: evraziyskiy aspekt [Perception of Russian authorities by the indigeneous population of Siberia in the 17th century: The Eurasian aspect]. Sibirskie istoricheskie issledovaniya - Siberian Historical Studies. 1. pp. 8-17.

5. Vladimirtsov, B.Ya. (1934) Obshchestvennyy stroy mongolov [The social system of the Mongols]. Moscow; Leningrad: USSR AS.

6. Anon. (2009) Sokrovennoe skazanie mongolov [Secret History of the Mongols]. In: Melekhin, A. (ed.) Chingisiana. Svod svidetel'stv sovremennikov [Chingisiana. The collection of evidence by the contemporaries]. Translated by A. Melekhin. Moscow: EKSMO. pp. 17-256.

7. Fedorov-Davydov, G.A. (1973) Obshchestvennyy stroy Zolotoy Ordy [The social system of the Golden Horde]. Moscow: Moscow State University.

8. Sherstova, L.I. (2014) Rossiya i Kitay: podkhody k pereosmysleniyu polietnichnosti [Russia and China: Rethinking the approaches to multiethnicity]. Vostokovednye issledovaniya na Altae. 8. pp. 185-189.

9. Konrad, N.I. (1996) Neopublikovannye raboty, pis'ma [Unpublished works, letters]. Moscow: ROSSPEN.

10. Potanin, G.N. (2013) Prostranstvo Severnogo Kazakhstana i Sibiri po dokumental'nym publikatsiyam G.N. Potanina [Northern Kazakhstan and Siberia in the documents of G.N. Potanin]. Tomsk: Tomsk State University.

11. Rashid-ad-Din. (2000) Sbornik letopisey [Collection of Histories]. Vol. 1(1). Moscow: Ladomir. 